\title{
Supporting Information - Controlling hydrogel properties by crystallization of hydrophobic domains
}

\author{
Naomi Sanabria-DeLong ${ }^{\dagger}$, Sarvesh K. Agrawal ${ }^{\ddagger}$, Surita R. Bhatia ${ }^{\ddagger \star}$, Gregory N. Tew ${ }^{\dagger \star}$ \\ University of Massachusetts-Amherst, †Polymer Science and Engineering Department, 120 Governors Dr. \\ †Department of Chemical Engineering, 159 Goessmann Laboratory 686 North Pleasant St., Amherst, MA 01003.
}

\section{Experimental Section}

General Method for PLA-PEO-PLA triblock reaction. PEO was obtained from Sigma Aldrich and dried under vacuum for a day prior to use. Both L-lactide and DL-lactide were also obtained from Sigma Aldrich, recrystallized in ethyl acetate, and sublimated prior to use. Tin octonoate catalyst from Alfa Aesar was used without further purification. Telechelic PEO macroinitiator (10.0 g, 1.14 mmol, 1 equiv) was weighed into a dry round bottom flask with a stir bar. The PEO was stirred and heated at $150^{\circ} \mathrm{C}$ while purged with nitrogen. Tin octonoate $(185 \mu \mathrm{L}, 0.57 \mathrm{mmol}, 0.5$ equiv) was added to the mixture, followed by immediate addition of L-lactide (6.9 g, $47.9 \mathrm{mmol}$, 42 equiv). The reaction was capped and reacted at $150^{\circ} \mathrm{C}$ for 24 hours. After cooling the reaction was quenched with methanol, diluted with tetrahydrofuran, and precipitated in hexanes. Dissolution and precipitation was repeated 3 more times. The recovered white powder was then dried under vacuum. ${ }^{1} \mathrm{H}$ NMR spectra were recorded with a $300 \mathrm{MHz}$ Bruker Spectrospin 300. Chemical shifts are expressed in parts per million using deuterated chloroform solvent protons as the standard. Gel permeation chromatography was performed with a Polymer Laboratories PL-GPC50 with 2 PLGel $5 \mu \mathrm{m}$ Mixed-D columns, a $5 \mu \mathrm{m}$ guard column, and a Knauer RI detector versus poly(styrene) standards. The eluent was $\mathrm{N}, \mathrm{N}$-dimethyl formamide with $0.05 \mathrm{M} \mathrm{LiCl}$ at $50{ }^{\circ} \mathrm{C} .{ }^{1} \mathrm{H} \mathrm{NMR}\left(300 \mathrm{MHz} \mathrm{CDCl}_{3}\right) \delta 5.16, \delta 3.62, \delta$ $1.59, \mathrm{M}_{\mathrm{n}}=13,958 ; \mathrm{GPC}(\mathrm{DMF}) \mathrm{PDI}=1.2$.

General method for Rheological data. In a typical method of preparation, nanopure water was added to a measured amount of polymer to make $25 \mathrm{wt} \%$ samples. These samples were kept at equilibrium for 1 day at room temperature and then heated at $40^{\circ} \mathrm{C}$ for 20 hours. The gels were again allowed to sit for 2 days before being transferred to a TA instruments AR2000 stress controlled rheometer for oscillatory measurements. Rheological measurements were performed using the cone and plate geometry (40 mm diameter cone with a $2^{0}$ cone angle). A solvent trap was used and water evaporation was not significant for the temperature and timescales investigated. Stress sweep at a constant frequency of $1 \mathrm{~Hz}$ was first performed to obtain the linear viscoelastic region for collecting subsequent data. Frequency sweep tests over a frequency range $0.01 \mathrm{~Hz}$ to $100 \mathrm{~Hz}$, were done at constant stress amplitudes to measure G' and G', (storage and loss moduli, respectively) corresponding to the linear response. The data in Figure 1 of the communication shows that the stereoregular sample forms a gel (G'> G') while the stereorandom sample does not. We use the common definition from the literature for our hydrogels. When G' > G' then the sample is considered a gel. This again indicates that the stereocenter plays an important role in gel formation. Figure SI1 shows another example in which the stereoregular polymer makes a stiffer gel than the stereorandom polymer. This is true even though the racemic polymer is two units longer than the stereoregular one. These sets of data show that the hydrogels' stiffness is increased when using stereoregular PLA and this is consistent even when the molecular weights are varied. All solutions were prepared as described above except for the $58 \mathrm{~L}$ and $60 \mathrm{R}$ samples. These are $25 \mathrm{wt} \%$ gels formed at $80^{\circ} \mathrm{C}$.

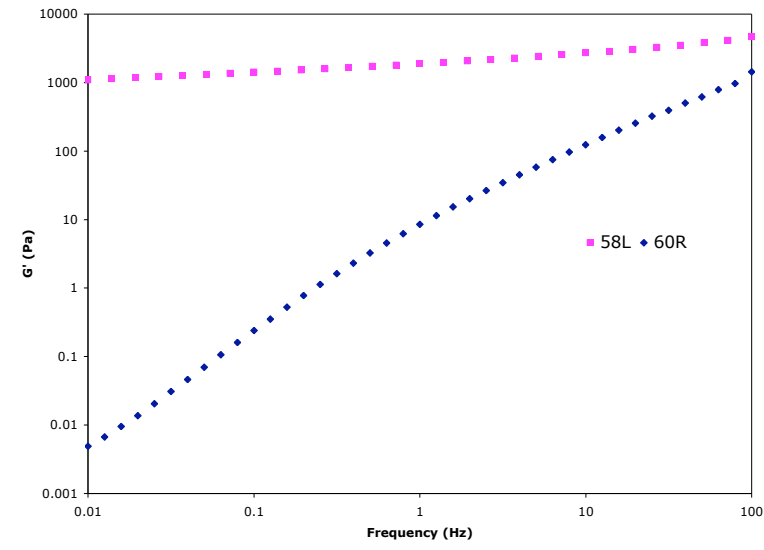

Figure SI1. A gel formed from a stereregular polymer with $\mathrm{DP}_{\mathrm{LA}}=58$ has a higher storage modulus than a gel formed from a stereorandom polymer with $\mathrm{DP}_{\mathrm{LA}}=60$. This is true even though the racemic polymer is two units longer than the stereoregular one. 
General Method for WAXD Data. Wide angle X-ray diffraction measurements of the gels from Figure $2(66 \mathrm{R}$ and $70 \mathrm{~L}$ at $20 \mathrm{wt} \%$ and formed at $40^{\circ} \mathrm{C}$ ) were performed on a Panalytical X'Pert Powder Diffractometer from $2 \theta=5^{\circ}$ to $60^{\circ}$. Figure SI2 shows a spectrum for two other triblock copolymer samples, 77L and 78R. The sample formed from stereorandom polymer shows no crystalline peaks while the sample formed from the stereregular polymer shows peaks at $2 \theta \approx 17^{\circ}$ and $19^{\circ}$ indicating crystalline PLLA. The broader peaks at $\sim 28^{\circ}$ and $\sim 42^{\circ}$ are from scattering of water (The scattering of water alone shows a spectrum that is almost identical to the racemic polymers).

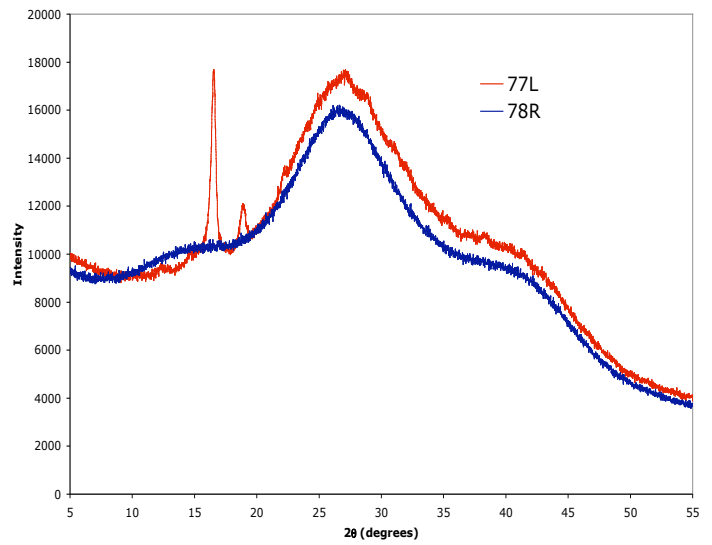

Figure SI2. A sharp peak at $2 \theta \approx 17^{\circ}$ is found in the gel formed from a stereoregular polymer that corresponds to crystalline PLLA. This peak is absent in the stereorandom gel. 
